\title{
The implementation of internal assessment mechanisms in the management of the educational program: ESG principles and new educational standards in the Russian Federation
}

\author{
Ivan Nikanorov ${ }^{1, *}$, and Antoniy Shvindt ${ }^{2}$ \\ ${ }^{1}$ Committee on Education and Science of the State Duma of the Russian Federation, 125009 Moscow, \\ Russia \\ ${ }^{2}$ Center for Innovative Educational Technologies, Moscow Institute of Physics and Technology (State \\ University), 141701 Moscow, Russia
}

\begin{abstract}
The purpose of this article is to describe possible approaches to transforming the management of the educational program into an educational institution of higher education in the context of implementing the principles laid down in the Standards and Recommendations for Quality Assurance in the European Higher Education Area (ESG), as well as the updated Russian state higher education standards (RSHES $3++$ ). The article analyzes the ESG, examines the main models of managing educational programs, as well as their possible transformations in terms of the formation of mechanisms for internal assessment of the quality of educational activities and the training of students, introduced in the updated federal state educational standards.
\end{abstract}

\section{Introduction}

The fourth industrial revolution, which led to a gradual transition to a new technological order, significantly changed the economy and the social sphere, placing the synthesis of the digital, physical and biological spheres in the focus of strategic development. All this significantly changed the idea of the disciplinary division of science, because the most endto-end technologies that have become most in demand one way or another affect a wide range of scientific fields and require a different approach to the organization of science and implementation mechanisms [1]. In a special way this fact updates the new model of the organization of education, since it requires new competencies, high learning speed, an individual trajectory and a flexible schedule that allows to combine training with production activities [2]. In this regard, the classical formalized system of organization of higher education undergoes transformation towards various forms of interaction between participants in educational relations and greater personalization, taking into account both

* Corresponding author: nikanorovin@gmail.com 
the needs of students and the need to constantly change professional competencies. This requires a significant transformation of the higher education systems of the CIS and BRICS countries, since they need not only a substantial restructuring of educational institutions, but also more effective integration into the global educational space $[3,4]$.

\section{The international context of changes in higher education}

The new challenges significantly changed the requirements for both the university and the graduate model, taking personal motivation and the ability to build an independent educational trajectory in a university environment as one of the most important conditions for successful learning. This made it possible to develop a unified approach to a set of requirements throughout the European Higher Education Area, which fixed the studentcentered approach as one of the basic principles of higher education. Following the results of the Ninth Conference of Ministers of Education of the European Higher Education Area (including Russia) held in Yerevan on May 14-15, 2015, the Standards and Recommendations for the Quality Assurance of Higher Education in the European Space were approved in a new version and the European approach to quality assurance of joint programs. The key standards in the context of the topic discussed in this article are standards $1.3,1.6$ and 1.9 [5].

In the standard 1.3 of this document the following principle is outlined: Studentcentered learning and assessment of achievement Standard: Universities should introduce student-centered learning processes into their programs. The methods by which programs are implemented should stimulate students to take an active role in the joint construction of the educational process.

According to the standard 1.6: Educational resources and the student support system Standard: Educational organizations must ensure that the educational resources and student support services are adequate, accessible and appropriate.

Recommendations for the inclusion of students in the internal assessment of the quality of education are outlined in Standard 1.9: Ongoing monitoring and periodic evaluation of programs. Standard: Universities should monitor and evaluate programs periodically in order to ensure that they reach their goal and meet the needs of students and society. The results of these processes should lead to a continuous improvement of programs. All interested persons should be informed of any planned or undertaken actions with respect to these programs.

Thus, we see that the context of the adoption of the Standards and the recommendations for quality assurance in the European Higher Education Area (ESG) is formed by the ever increasing demands of the society and the learners themselves for the system and the quality of education, the diversification of possible educational trajectories and the development of various forms and ways of obtaining both a formal, and informational education. ESGs presuppose the formation of approaches focused primarily on the student, the search for the most flexible educational trajectories and the recognition of competences acquired outside formal education. The implementation of the above ESG provisions aimed at the student is impossible without the formation of a community of students who are specifically involved in assessing and improving the quality of education, expanding the toolkit of student evaluation, and developing mechanisms for taking this assessment into account both in internal and external evaluation of the quality of education, therefore, the relevance of the development of student bodies (organizations) in the quality of education in the countries of the European Higher Education Area will only increase. 


\section{Implementation of ESG principles in the Russian education system}

The development of state-public interaction in the management of Russian education over the past decades gives grounds to say that a special type of government has been formed: state-public. It is characterized by the fact that subjects implementing policies in the field of education and educational organizations carry out constant interaction in the management education and provision of educational services with subjects representing the interests of society and the population, with their responsible participation in this activity. The task of the state is to provide all the necessary prerequisites for expanding the participation of society in the development of the education system, the formation of a public request for the conditions for the implementation of educational rights, monitoring the implementation of legislation on education, the implementation of state educational standards, the allocation of responsibility for the activities of all participants in legal relations in this sphere.

According to paragraph 29 of article 2 273-FZ The quality of education is understood as a complex characteristic of the educational activity and training of the student, expressing the level of their compliance with Russian federal state educational standards, educational standards, federal state requirements and (or) the needs of the individual or legal entity in whose interests educational activities are carried out, including the degree of achievement of the educational program planned results;

Under the physical person, in whose interests educational activity is carried out in the system of higher education, it is meant to understand the student, and under the legal entity - the employer. Accordingly, the law presupposes the possibility of participation of each of the categories of interest in the process of evaluation and improvement of the quality of education, both external and internal.

Nevertheless, it should be noted that the norms of inclusion of students in the processes of education quality internal assessment, fixed in the formulations of the federal law on education, were not reflected in the existing mechanisms for organizing the educational activity of universities, regulated by subordinate regulatory legal acts, such as, for example, federal state educational standards, and, accordingly, in the procedures for state assessment of the quality of education. Thus, the principles of student-centered instruction and the inclusion of students in monitoring the quality of education laid down in the ESG, as well as in the federal law on education, were not fully implemented in the practice of educational results, because of their consolidation in normative legal acts of the Ministry of Education and Science of the Russian Federation. However, this problem can be resolved in the Russian state higher education standards in the new edition (RSHES $3++$ ), developed and approved by now for the majority of training areas, which are enacted from September 1,2018 . In the updated standards the corresponding possibilities are provided in paragraph 4.6.2:

4.6.2. In order to improve the Bachelor's program, the Organization, in carrying out a regular internal assessment of the quality of educational activities and training of students in the bachelor's program, attracts employers and (or) their associations, other entities and (or) individuals, including the teaching staff of the Organization.

Such an approach has already been implemented by educational organizations as an initiative even before its normative consolidation in RSHES [6].

Within the framework of the internal system of assessing the quality of educational activity under the bachelor's program, students are given the opportunity to assess the conditions, content, organization and quality of the educational process in general and individual disciplines (modules) and practices. This provides ample opportunities for the implementation of the student position in various management tools of the university: an 
effective contract of faculty, university self-examination procedures and others at the discretion of the educational organization.

At the same time, this will significantly change the procedure for state accreditation of educational programs, first proposing a mechanism for evaluating the principles of involving students in assessing the quality of education and implementing a studentcentered approach to learning.

\section{Model of students' participation in quality assurance of education}

Let us consider the model of participation of students in various procedures for guaranteeing the quality of higher education in the context of maximum applicability to the Russian educational environment. It should be noted that the European practice, formed in the framework of the EHEA, examines students from several positions, determined by a various role, function and status [7]:

Student as an information provider:

Feedback is one of the most common ways of involving students in internal quality assurance procedures for higher education. At present, different models are implemented in universities in what way, when and what kind of feedback students provide. The most common way of feedback is after each training course or at least once a semester.

Student as an actor:

Some of the most motivated students are ready to participate as an actor of intrauniversity quality assurance procedures, and not just act as providers of information. students themselves participate in the development of the questionnaire or do it in close cooperation with the academic and administrative staff of the university. They can be involved in the collection and analysis of feedback data, as well as organizing joint training seminars for teachers and students, as well as offering projects aimed at solving current problems and tasks.

Student as experts:

Given that ESG is subject to quality assurance is the quality of education, not teaching, the role of students in this process is significant. Students themselves can better analyze how teaching helped them achieve their educational results. This allows a number of agencies to guarantee the quality of education to evaluate teaching through the experience of teaching students, based on how it actually helps to effectively organize the learning process. The use of the proposed expert evaluation of students in a specific form involves the application of certain procedures, such as, for example, involving students in working groups and collegiate bodies with the right to vote. The attitude towards students as experts is a consequence of a culture that requires a positive perception from both the academic community and the students themselves.

Currently, the possibility of participation of students as experts in the accreditation of educational programs is substantially limited by the current regulatory and legal framework that defines the requirements for experts and the procedure for examination.

Thus, the adoption of new RSHES will allow to fully implement the principles of internal guarantee of the quality of education in Russia and the participation of students in this process, making them fully responsible for the learning process and the choice of the educational trajectory. The mechanisms of external quality assurance of education in Russia (state accreditation of educational programs) are still archaic, it is likely that it will require a substantial change both in the model itself and in the requirements for experts, including through the inclusion of students and employers in the academic composition of the commission. All this should make the system of higher education in the Russian Federation 
more dynamic and flexible, allowing to respond to the current challenges facing the educational system.

\section{Conclusions}

The opportunities, provided by the updated federal state educational standards for higher education, for students to participate in the internal system for assessing the quality of education create the necessary regulatory prerequisites for implementing the academic rights of students enrolled in the management of an educational organization enshrined in the federal law on education, and will open the possibilities for implementing the relevant ESG points in practice of creating and improving educational higher education programs.

\section{References}

1. M. Hermann, P. Tobias, B. Otto, 49th Hawaii International Conference (2016)

2. M. Solovyev, K. Mertins, A. Shagdyrov, MATEC Web of Conferences, 01034 (2017)

3. A. Huisman, A. Smolentseva, I. Froumin, Palgrave Macmillan, (2018)

4. I. Froumin, O. Leshukov, Palgrave Macmillan, Ch. 8 (2016)

5. Standards and Guidelines for Quality Assurance in the European Higher Education Area (ESG). Brussels, Belgium. (2015)

6. M. Balyasin, L. Carvalho, G. Mihut, Voprosy obrazovaniya / Educational Studies. Moscow, 1, 110 (2016)

7. A. Klepikov, K. Mertins, A. Khasenova, LXXXII International Research and Practice Conference and II stage of the Championship in Psychology and Educational sciences (2014)

8. H. Alaniska, E. A. Codina, J. Bohrer et al., ENQA. Helsinki, (2006) 